REVISTA DE DERECHO UNED, NÚM. 14, 2014

\title{
RECIENTES MODIFICACIONES EN EL DERECHO ESPAÑOL SOBRE LA TUTELA DEL CONSUMIDOR TRAS LA LEY 3/2014, DE 27 DE MARZO, POR LA QUE SE MODIFICA EL TRLCU. ESPECIAL REFERENCIA AL DERECHO DE DESISTIMIENTO
}

\begin{abstract}
RECENT CHANGES IN THE SPANISH LAW ABOUT CONSUMER PROTECTION AFTER LAW 3/2014, OF 27 MARCH, WHICH MODIFIES THE TRLCU. SPECIAL REFERENCE TO THE RIGHT OF WITHDRAWAL
\end{abstract}

Yolanda Aguilar Olivares

Técnico Especialista en Consumo. Doctoranda en el Programa de «Derecho y Ciencias Sociales», UNED

Resumen: La reciente publicación de la Ley 3/2014, de 27 de marzo, por la que se modifica el texto refundido de la Ley General para la Defensa de los Consumidores y Usuarios y otras leyes complementarias, aprobado por el Real Decreto Legislativo 1/2007, de 16 de noviembre ha supuesto la trasposición a nuestro derecho interno de la Directiva 2011/83/UE. La Directiva 2011/83/UE del Parlamento Europeo y del Consejo, de 25 de octubre de 2011, sobre los derechos de los consumidores, por la que se modifican la Directiva 93/13/CEE del Consejo y la Directiva 1999/44/CE del Parlamento Europeo y del Consejo y por la que se derogan la Directiva 85/577/CEE del Consejo y la Directiva 97/7/CE del Parlamento Europeo y del Consejo ha supuesto el impulso a la protección de los consumidores y usuarios europeos y a la consolidación del mercado interior dotando tanto a los consumidores como a los empresarios de una mayor seguridad jurídica. Pretende caminar hacia la armonización plena de los ordenamientos jurídicos internos de los Estados, y para ello ha introducido 
modificaciones sustanciales en materia de contratos con los consumidores y usuarios, ha derogado la normativa relativa a los contratos celebrados a distancia y los contratos celebrados fuera de los establecimientos mercantiles y determinados aspectos de la venta y las garantías de los bienes de consumo, con una regulación más amplia del derecho de desistimiento.

Palabras claves: derecho de información, derecho de desistimiento, consumidor, comerciante y contratos a distancia y contratos fuera de establecimiento mercantil.

Abstract: The recent publication of Law 3/2014, of 27 of March, by which the recast of the General Law for the Defense of the Consumers and Users is modified and other complementary laws, approved by Real Legislative Decree 1/2007, of 16 of November has meant the transposition to our national right. The Directive 2011/83/UE of the European Parliament and the Council, of 25 of October of 2011, on the rights of consumer, by which the Directive 93/13/CEE of the Council and the Directive 1999/44/CE of the European Parliament and the Council and the Directive 85/577/CEE of the Council and the Directive 97/7/CE of the European Parliament and the Council are been modified, has supposed an impulse to the protection of the European consumers and users and to the consolidation of the domestic market providing both the consumers and the entrepreneur with a greater legal security. It pretends to walk towards the complete harmonization of the domestic legal system of the States and for this reason it has introduced substantial modifications in the matter of contracts with the consumer and users, it has abolished the norm relative to celebrated contracts at a distance contracts and off -premises contracts and certain aspects of the sale and the guarantees of the consumer goods, with a broader regulation of the right of withdrawal.

Keywords: Right of withdrawal, consumer, entrepeneur, trader, retailer, terms of exercise, distance contracts, off premises contract.

Sumario: I. Consideraciones previas. II. La Directiva 2011/83/UE del Parlamento Europeo y del Consejo, de 25 de octubre de 2011 sobre los Derechos de los Consumidores. III. Nuevos planteamientos en el Derecho Español en la tutela del consumidor: El anteproyecto de ley por el que se modifica el texto refundido de la Ley General para la Defensa de Consumidores y Usuarios y Otras Leyes Complementarias, aprobado por el Real Decreto Legislativo 1/2007. III.1. Preliminar. III.2. Principales modificaciones introducidas por el anteproyecto. 
III.2.A. Deber de información. III.2.B. Entrega de bienes. III.3.C. Contratos a distancia y contratos fuera de establecimiento mercantil. III.4.D. Derecho de desistimiento. IV. Conclusiones.

Recepción original: 10/04/2014

Aceptación original: 27/05/2014

\section{CONSIDERACIONES PREVIAS}

El presente trabajo se sitúa en el marco de las recientes modificaciones que se están produciendo en materia de defensa de los consumidores y usuarios, como consecuencia de la publicación de la Ley 3/2014, de 27 de marzo, por la que se modifica el texto refundido de la Ley General para la Defensa de los Consumidores y Usuarios y otras leyes complementarias, aprobado por el Real Decreto Legislativo $1 / 2007$, de 16 de noviembre.

En efecto, la Ley 3/2014, de 27 de marzo, modifica el Texto Refundido de la Ley General para la defensa de consumidores y usuarios y otras leyes complementarias, aprobado por el Real Decreto Legislativo $1 / 2007$, de 16 de noviembre y que tiene por objeto la transposición de la Directiva comunitaria 2011/83/UE.

Es sabido que, los orígenes de la Directiva se remontan a 2001 y en concreto, al proceso de consulta pública sobre las diferencias entre el derecho contractual de los Estados Miembros formulado por la Comisión Europea. Posteriormente y con motivo del resultado de la consulta, la Comisión publicó en el año 2003 el Plan de Acción en el que creó el llamado Marco Contractual Europeo para el derecho contractual y la revisión del acervo en materia de Derecho Contractual de consumo.

En este sentido, es una idea pacifica que cuando nos referimos al derecho contractual europeo y al derecho de consumo en particular, hablar de cierta uniformidad y unanimidad en el tratamiento es un tanto complicado. El propio Plan de Acción del 2003, Comunicación de la Comisión al Parlamento Europeo y al Consejo sobre un derecho contractual europeo más coherente, supuso el punto de partida para tratar el ámbito de aplicación del mismo.

Como la doctrina ha señalado, el objetivo de la Comisión era lograr antes de 2013 un mercado interior más integrado y eficaz, sobre todo en lo relativo a la dimensión minorista. En este marco, los mercados de consumo deberían ser transparentes, competitivos, abiertos y justos a la vez que los productos y servicios serían seguros y los

(C) UNED. Revista de Derecho UNED, núm. 14, 2014 
consumidores tendrían acceso a los servicios esenciales a precios asequibles.

La pretendida unificación del Derecho Privado de los contratos, tomando como base y respeto el derecho de protección de los consumidores, se puede decir que es uno de los fenómenos más interesantes y de hondo calado que se están desarrollando en el campo del Derecho, merced en gran medida al impulso que la armonización del derecho comunitario está llevando a cabo.

En este contexto y tal como afirma Leible ${ }^{1}$, se trata de elaborar un Código Civil Europeo que regula las relaciones contractuales, extracontractuales y parte de los derechos reales, que sirve como Marco común de referencia. Señala el autor citado que «Un mercado interior comprometido con el principio de una economía de mercado abierta con la libre competencia es, sin la autonomía privada, algo impensable.»

Se pueden citar entre todas las propuestas, La Comisión en Derecho Contractual Europeo (comisión Lando) ${ }^{2}$, redactora de los principios de Derecho Contractual Europeo I-II-III cuyos sucesores son el Grupo de Estudios sobre un Código Civil Europeo (Von BaR, del mismo modo se encuentra la Academia de Privatistas Europeos (Proyecto en Pavía, GANDOLFI) que ha elaborado el Código de Contratos y el Proyecto en Trento, en Common Core of European Private Law. ${ }^{3}$

Entre las medidas comunitarias de impulso de un contexto normativo armonizador pueden destacarse Resoluciones desde 2003, siendo las últimas a destacar el Libro Verde de la Comisión de 1 de julio de 2010 sobre las acciones contempladas para avanzar hacia un Derecho contractual europeo para consumidores y empresas ${ }^{4}$ y la Resolución del Parlamento Europeo sobre opciones para avanzar hacia un derecho contractual europeo para consumidores y usuarios de 18 de abril de 2011.

Como es bien sabido, el Marco Común de Referencia (en adelante MCR) pretende establecer un sustrato básico que contenga definiciones de conceptos jurídicos, principios fundamentales y preceptos coherentes, sobre la base del acervo comunitario y las soluciones

${ }^{1}$ LeIBLE Stefan, "Vías para la unificación del Derecho privado europeo», Conferencia pronunciada en la Universidad Pablo de Olavide el 1 de junio de 2006 en el marco de unas «Jornadas sobre Derecho Privado Europeo.» 2006, pp. 1589 y ss.

${ }^{2}$ Kluner Law International, La Haya, 2000, Presidente: Profesor Landó.

${ }^{3}$ Orozco Pardo, Guillermo y Moral Navarrete, Miguel., "El contrato en el contexto de la unificación del derecho privado». Anales de Derecho, 2011.

${ }^{4}$ (COM (2010) 348 final. 
empíricas que sirvan para el legislador estatal y comunitario en materia de contratos, así como la interpretación por Tribunales y el TJC del Derecho Contractual Europeo, siendo aplicable incluso a los procedimientos arbitrales.

Se trataría en definitiva, de un instrumento jurídico facultativo no obligatorio, pero elegible por las partes frente a normas internas disponibles y en las relaciones de carácter supranacional, que se plasmaría en los formularios contractuales de contratos típicos específicos. ${ }^{5}$

Realmente, el MCR coincide en el tiempo con los principios de derecho comercial Internacional de UNIDROIT, pasando aquellos a un segundo plano. Según el Grupo de Estudio del Código Civil Europeo y el Acquis Grupo 6 , la formulación de objetivos y principios fundamentales revela el modelo de sociedad y el sistema económico más directamente que las reglas individuales.

En los años posteriores se procedió a la revisión del acervo en materia de consumo y culminó con la publicación en 2007 de la publicación del «libro verde sobre la revisión del acervo en materia de consumo con el que se concluyo la fase de revisión y en 2011 se publicó la Directiva 2011/83/UE.

En resumen, los textos comunitarios que han abierto el proceso de consulta y reflexión para adoptar las nuevas medidas han sido, por un lado, la Comunicación de la Comisión Europea sobre derecho contractual europeo de 11 de julio de 2001, y por otro, el Libro Verde sobre la protección de los consumidores de la UE de 2001, (ésta última tiene como objetivo analizar, actualizar, simplificar y dar coherencia a las directivas de consumo existentes). Pero, como es bien sabido, hasta el momento las Directivas solo han tratado temas concretos o negocios específicos. La tendencia del mercado ha evolucionado y el consumidor nacional cada vez se convierte más en un consumidor europeo, consecuencia de la unificación de la moneda y la expansión del comercio electrónico con la implantación de internet.

Sin embargo, como pone de relieve el Libro Verde sobre Protección del Consumidor 2001, los consumidores no se están beneficiando plenamente del mercado interior, como se refleja en el bajo número de negocios transfronterizos, por lo que la Comisión Europea entiende que es el momento de cambiar de estrategia, y ello conlleva necesariamente un cambio en la estrategia legislativa.

\footnotetext{
${ }^{5}$ Diéguez Oliva, Rocío., «El derecho de desistimiento en el marco común de referencia», Indret, n. ${ }^{\circ}, 2009$, págs., 2-20.

${ }^{6}$ www.acquis-group.org.
} 
Por tanto, el llamado déficit armonizador, en los términos expuestos, se pretende cubrir con iniciativas relativas a un derecho contractual europeo coherente.

Por ello, y a pesar de los distintos intentos armonizadores que se han producido, incluso con el impulso en 1989 para la elaboración de un código europeo de Derecho Privado; se ha limitado a la aprobación de disposiciones particulares de protección de los consumidores. La doctrina ha estudiado diversas propuestas y entre ellas se encontraba la de continuar el modelo americano de los «restataments» del derecho norteamericano (especie de compilaciones de carácter privado, American Law Institute, que sintetizan, de manera metódica y sistemática en un ámbito jurídico particular contratos, daños, propiedad).

Como señala Patti ${ }^{7}$, el sistema del Código Civil que se ha buscado en Europa choca con el sistema de armonización más utilizado en la materia de consumo que subyace en la Directiva. Esta fórmula atiende a las diferencias de cada país, como indica el autor, por un lado, Europa busca la armonía, la igualdad en la elaboración de un Código Civil y, por otro, en materia muy concretas como es el consumo se aparta y dicta Directivas concretas para regular materias como las cláusulas abusivas o la publicidad engañosa.

A la vista de tal situación, La Comisión Europea publicó, el 1 de julio de 2010, el Libro Verde sobre opciones políticas para avanzar hacia un Derecho contractual europeo para los consumidores y usuarios y las empresas, en el que propone, dada la disparidad de normativa existente, de un marco común del derecho contractual europeo.

En este sentido, la perspectiva de futuro es la de facilitar las transacciones transfronterizas evitando la multiplicidad de ordenamientos jurídicos, señala el Libro Verde, «un instrumento de Derecho contractual europeo que sea suficientemente fácil de utilizar y jurídicamente seguro, podría también servir de modelo, especialmente para los organismos internacionales que han tomado a la Unión como modelo de integración regional. La Unión podría así desempeñar un papel protagonista para establecer normas internacionales uniformes en esta materia, lo que, a su vez, podrá dar a la economía europea una ventaja competitiva en el mundo».

Este libro Verde plantea diferentes formas de llevar a cabo la regulación del derecho contractual europeo, pero, como en otras ocasio-

${ }^{7}$ PatTI, Salvatore., «Diritto Privato e Codificazioni Europee», Giuffré Editore-Milano 2004. 
nes, encuentra en la Directiva la mejor forma de regular el derecho contractual europeo.

\section{LA DIRECTIVA 2011/83/UE DEL PARLAMENTO EUROPEO Y DEL CONSEJO, DE 25 DE OCTUBRE DE 2011 SOBRE LOS DERECHOS DE LOS CONSUMIDORES}

Pese a la amplitud de miras que en principio pudiera derivarse de la propia denominación de la Directiva 2011/83/UE, que pretendía revisar el acervo normativo existente hasta la fecha en materia de tutela del consumidor, lo que se concretaba en la revisión y armonización de cuatro Directivas, en concreto, la Directiva 2011/83/UE del Parlamento Europeo y del Consejo, de 25 de octubre de 2011 sobre los derechos de los consumidores por la que se modifica la Directiva 93/13/CEE del Consejo y la Directiva 99/44/CE del Parlamento Europeo y del Consejo y se derogan la Directiva 85/577/CEE del Consejo y la Directiva 97/7/CE del Parlamento Europea y del Consejo, finalmente solo revisó y armonizó dos (Directiva 85 y Directiva 97), manteniendo las otras dos, si bien con modificaciones (Directiva 93 y Directiva 99). ${ }^{8}$

Es sabido que, las Directivas conforme al artículo 249 del Tratado constitutivo de la Comunidad Europea, indica que «la directiva obligará al Estado miembro destinatario en cuanto al resultado que deba conseguirse, dejando sin embargo, a las autoridades nacionales la elección de la forma y de los medios» ${ }^{9}$.

Por ello, la directiva es una norma de resultado que no condiciona ningún elemento, formal o material, del proceso de cada Estado para llevar a cabo la transposición de la misma a cada uno de los Derechos nacionales. Los Estados miembros deben elegir la forma adecuada para la adaptación, interpretar adecuadamente el objetivo que la directiva impone y hacerlo en el plazo establecido. Ahora bien, como es bien sabido, los problemas se presentan cuando el Estado miembro no transpone la directiva en el plazo previsto. ${ }^{10}$

La citada Directiva 2011/83/UE sin perjuicio del Reglamento CE 593/2008 del Parlamento Europeo y del Consejo, de 17 de junio

${ }^{8}$ Domínguez Pérez, Eva., «Recientes planteamientos de tutela del consumidor mediante el ejercicio del derecho de desistimiento» Revista de Derecho de la Unión Europea, n. ${ }^{\circ} 26,1 .^{\circ}$ emestre, 2014, Uned.

9 Mellado Prado, P., Linde Paniagua, E., y Gómez de Liaño Fonseca, M.,»Instituciones del Derecho Comunitario», Madrid, Colex, 2012.

${ }^{10}$ La sentencia de 12 de noviembre de 1974, caso Friedrich Haaga Gmbh como criterio de interpretación del derecho interno. 
de 2008, sobre la ley aplicable a las obligaciones contractuales, deroga la normativa europea vigente sobre la protección de los consumidores en dos contratos específicos; así en los contratos a distancia y en los contratos celebrados fuera de los establecimientos mercantiles, apostando por un nuevo marco legal en esta materia, y conjuntamente modificando la normativa europea sobre cláusulas abusivas en los contratos celebrados con consumidores y sobre determinados aspectos de la compraventa de bienes y servicios de consumo, y sobre las garantías de los mismos.

Es importante, además el contenido del considerando 13 de la Directiva, que deja abierto a los Estados Miembros la posibilidad que se haga extensible dicha Directiva a campos contractuales no recogidos en la misma; Por ello, podrá aplicarse a los no consumidores en base al concepto que se da en la citada norma, deja abierto a «otros no consumidores» que sí lo son por ejemplo en nuestra norma de protección de los consumidores donde la definición del consumidor es amplia y extensa como señalaba el profesor Bercovitz, ${ }^{11}$

Igualmente la Directiva realiza una explicación extensa de lo que debe entenderse por establecimiento mercantil y empresario.

Para aprehender totalmente el sentido de la Directiva nos debemos de remontar al año 2007 cuando se publica el Libro Verde sobre la revisión del acervo en materia de consumo, de fecha 8 de febrero de 2007, que tuvo como objetivo la revisión de ocho Directivas sobre la protección de los consumidores y expuso varias tipos de alternativas; así entre ellas se encontraba la de instrumentalizar a través de una norma de rango horizontal,-que se aplica a todos los contratos celebrados entre consumidores y empresarios-, sin perjuicio de que contenga disposiciones especificas para unos determinados contratos como son en este caso a los contratos a distancia y contratos celebrados fuera de establecimiento.

La Directiva se aplica a los contratos celebrados entre consumidores y empresarios, así lo establece el artículo 1 y 3.1 de la Directiva, para continuación recoger el concepto de consumidor y comerciante. Y en el artículo 3.1 establece el ámbito de aplicación objetivo, que se circunscribe a todos los contratos celebrados entre un comerciante y un consumidor.

${ }^{11}$ Bercovitz Rodríguez-CANo, A., «Ámbito de aplicación y derechos de los consumidores y usuarios en la Ley General para la Defensa de los Consumidores y Usuarios», Revista de Estudios de Consumo, número 3. ${ }^{\circ}$ 1984, págs. 20-38. 
Como resumen del contenido de los capítulos de la Directiva, podemos indicar que él; Capitulo I, contiene las definiciones que hemos señalado anteriormente y el ámbito de aplicación, el capítulo II contiene información precontractual en los contratos a distancia o en los contratos celebrados fuera de establecimiento mercantil, mientras que el capítulo III se aplica específicamente a los contratos anteriormente mencionados y regula el derecho de desistimiento; el capítulo IV regula lo relativo a la fase de ejecución del contrato; y el capítulo V contiene normas técnicas mientras el capítulo VI incluye disposiciones finales, que contiene una cláusula derogatoria, la fecha de entrada en vigor de la Directiva, y la modificación de las Directivas 93/13/CEE y 1999/44/CE.

Finalmente merece especial atención el artículo 3.1 relativo al ámbito de aplicación de la mencionada norma, que abarca incluso a los contratos de suministro de agua, gas, electricidad y calefacción mediante sistemas urbanos, incluso por parte de proveedores públicos, en la medida en que esas mercancías se suministran sobre una base contractual.( «La presente Directiva se aplicará, en las condiciones y en la medida fijadas en sus disposiciones, a los contratos celebrados entre un comerciante y un consumidor. Se aplicará igualmente a los contratos de suministro de agua, gas, electricidad y calefacción mediante sistemas urbanos, incluso por parte de proveedores públicos, en la medida en que esas mercancías se suministren sobre una base contractual).»

III. NUEVOS PLANTEAMIENTOS EN EL DERECHO ESPAÑOL EN LA TUTELA DEL CONSUMIDOR: LA LEY 3/2014, DE 27 DE MARZO, POR EL QUE SE MODIFICA EL TEXTO REFUNDIDO DE LA LEY GENERAL PARA LA DEFENSA DE CONSUMIDORES Y USUARIOS Y OTRAS LEYES COMPLEMENTARIAS, APROBADO POR EL REAL DECRETO LEGISLATIVO 1/2007.

\section{III.1. Preliminar}

En esta ocasión la modificación del TRLGDCU tiene como objeto la transposición de la Directiva comunitaria 2011/83/UE que deroga las Directivas 85/577/CEE y 97/7/ CE que hemos comentado anteriormente, y supone la modificación de una importante parte del articulado del TRLGDCU, tal como indica la exposición de motivos que se reproduce seguidamente, 
«...Con fecha 22 de noviembre de 2011 se publicó en el Diario Oficial de la Unión Europea la Directiva 2011/83/UE del Parlamento Europeo y del Consejo de 25 de octubre de 2011, sobre los derechos de los consumidores, por la que se modifican la Directiva 93/13/CEE del Consejo y la Directiva 99/44/CE del Parlamento Europeo y del Consejo y se derogan la Directiva 85/577/CEE del Consejo y la Directiva 97/7/CE del Parlamento Europeo y del Consejo.

Puede afirmarse que la directiva supone un nuevo impulso a la protección de los consumidores y usuarios europeos y la consolidación de un mercado interior, dirigido a reforzar la seguridad jurídica, tanto de los consumidores como de los empresarios, eliminando disparidades existentes en la legislación europea de los contratos de consumo que crean obstáculos significativos en el mercado interior. Con esta finalidad, la Directiva amplía la armonización de los ordenamientos internos de los Estados bajo un enfoque de «armonización plena», con excepciones puntuales, e introduce modificaciones sustanciales en la vigente normativa europea en materia de contratos refundido de la Ley General para la Defensa de los Consumidores y Usuarios y otras leyes complementarias...»

«...La ley procede a regular conjuntamente los contratos celebrados a distancia y los contratos celebrados fuera de los establecimientos mercantiles, siguiendo la técnica jurídica utilizada por la Directiva. De esta forma, se hace preciso modificar el libro II del texto refundido, unificando la regulación de ambos tipos de contratos en su título III, lo que conlleva la eliminación del título V, cuya denominación y contenido pasa ahora al título IV.

Seguidamente, la Ley regula los requisitos formales de los contratos a distancia y de los contratos celebrados fuera del establecimiento mercantil y contempla la exigencia, más que reclamada por otro lado, de que los sitios web de comercio indiquen de modo claro y legible, si se aplica alguna restricción de suministro y cuáles son las modalidades de pago que se aceptan. Además el consumidor deberá al efectuar el pedido confirmar expresamente que es consciente de que dicho pedido implica, en su caso, una obligación de pago.

Con todo ello, mediante la nueva normativa se pretende modificar el texto refundido de la Ley General para la Defensa de los consumidores y usuarios y otras leyes complementarias, a fin de transponer al Derecho interno la Directiva 2011/83/UE.

Merece especial atención que, el legislador español no incorpora el concepto de contratos de suministro de agua, gas y la electricidad no envasado o contenidos digitales en soporte no material, quedando por 
ello sin definir. A contrario la Directiva en su artículo 3.1, relativo al ámbito de aplicación de la mencionada norma señala que abarca a los contratos de suministro de agua, gas, electricidad y calefacción mediante sistemas urbanos, incluso por parte de proveedores públicos, en la medida en que esas mercancías se suministran sobre una base contractual. «La presente Directiva se aplicará, en las condiciones y en la medida fijadas en sus disposiciones, a los contratos celebrados entre un comerciante y un consumidor. Se aplicará igualmente a los contratos de suministro de agua, gas, electricidad y calefacción mediante sistemas urbanos, incluso por parte de proveedores públicos, en la medida en que esas mercancías se suministren sobre una base contractual.»

\section{III.2. Principales modificaciones introducidas por la ley $3 / 2014$, de 27 de marzo}

\section{III.2.1. Deber de información}

Puede afirmarse que uno de los objetivos del nuevo texto legislativo es un considerable incremento en la información que recibe el consumidor; y es como era lógico prever, existe por parte del legislador europeo y español una honda preocupación por dotar al consumidor de mayores instrumentos para que pudiera operar en el tráfico comercial, ya que los estudios y análisis realizados desde la U. E desvelaban la escasa confianza y seguridad jurídica que muestra el consumidor en el marco de las relaciones comerciales transfronterizas.

Recordemos que ya el Texto Refundido aludido destacó en su Exposición de Motivos la preocupación del legislador por la imposición en las relaciones contractuales con los consumidores de obstáculos onerosos o desproporcionados para el ejercicio de los derechos reconocidos en el contrato, y en coherencia además con lo previsto en la Directiva 2005/29/CEE del Parlamento Europeo y del Consejo de 11 de mayo de 2005, sobre prácticas comerciales desleales, que prohíbe los obstáculos no contractuales para el ejercicio de tal derecho.

El Texto Refundido de la Ley General para la Defensa de los consumidores y usuarios aprobado por Real Decreto Legislativo 1/2007, de 16 de noviembre recogía en su artículo 60 la información previa al contrato, pero el nuevo texto modifica el elenco de información que debe aportarse al consumidor con tres apartados ( $\mathrm{i}, \mathrm{j}, \mathrm{K}$ ) «relativos a la funcionalidad de los contenidos digitales, incluidos las medidas de protección aplicables. A los efectos de esta norma se entiende por conte-

(C) UNED. Revista de Derecho UNED, núm. 14, 2014 
nido digital los datos producidos y suministrados en formato digital; cuando proceda, toda interoperabilidad relevante del contenido digital con los aparatos y programas conocidos por el empresario o que quepa esperar razonablemente que este pueda conocer; y el sistema de tratamiento de las reclamaciones del empresario, así como, en su caso, la información sobre el sistema extrajudicial del resolución de conflictos previsto en los servicios de atención al cliente.»

Por consiguiente, la información a disposición del consumidor tendrá que ser relevante, comprensible y clara, el legislador español sigue la misma línea de redacción que en la primera Ley de tutela del consumidor, la ley 26/1984 de 19 de julio, General de Defensa de los Consumidores y Usuarios, el antiguo artículo $7 .^{\circ}$ señalaba que la información que se contenía en la oferta, promoción o venta debía ser veraz, comprensible y clara para los consumidores y usuarios; pues bien en los mismos términos, pero con mayor precisión, se recoge en el Texto Refundido de la Ley General para la Defensa de los consumidores y usuarios aprobado por Real Decreto Legislativo 1/2007, de 16 de noviembre en los artículos 20, 21 y 60 (nuevos artículos 21, 60 y 97 TRLGDC).

En consecuencia, puede afirmarse que con la nueva normativa se amplía la información precontractual exigible en los contratos con los consumidores y usuarios, y a mayor abundamiento en los contratos a distancia y en los contratos celebrados fuera del establecimiento del empresario, que han sido objeto de plena armonización por parte de la Directiva comunitaria. Dentro de esta información es importante destacar la información facilitada a los consumidores y usuarios en relación con la existencia y condiciones de los depósitos u otras garantías financieras que, en su caso, tengan que pagar o aportar a solicitud del empresario, incluidas aquellas por las que se bloquee un importe en la tarjeta de crédito o débito del consumidor. También deberán de informar de la existencia de garantía legal de conformidad con los bienes, así como de la existencia y condiciones de los servicios postventa y de las garantías comerciales que otorguen, en su caso. Igualmente en los contratos de suministro de contenido digital deberán de informar de la funcionalidad del mismo, incluidas las medidas técnicas de protección aplicables, así como de toda interoperabilidad relevante con los aparatos y programas conocidos por el empresario o que quepa razonablemente esperar que deba conocer.

Asimismo añade un artículo 60 bis relativo a pagos adicionales, en el que el empresario deberá obtener el consentimiento expreso del 
consumidor para todo pago adicional a la remuneración acordada para la obligación contractual principal.

Por último destacar la importancia de la incorporación de dos artículos exclusivamente dedicados a regular los pagos adicionales requiriendo el consentimiento expreso del consumidor y los cargos por la utilización de los medios de pago, supuestos éstos que no son sino manifestaciones del incremento informativo para el consumidor.

\section{III.2.2. Entrega de bienes}

La nueva normativa se introduce en los artículo 66 bis y 66 ter, bajo la rúbrica «entrega de bienes y transmisión del riesgo»; concediendo al consumidor nuevos derechos en cuanto al plazo de entrega máximo de 30 días naturales a partir de la celebración del contrato, así como en cuanto a la forma de entrega, el riesgo de pérdida o deterioro de los bienes se transmitirá al consumidor cuando él o un tercero por él indicado, distinto del transportista haya adquirido su posesión material.

\section{III.2.3. Contratos a distancia y fuera de establecimiento mercantil}

Estos contratos han sido objeto de plena armonización por parte de la Directiva comunitaria y el nuevo texto incorpora dentro de los contratos a distancia aquellos contratos celebrados entre el empresario y el consumidor exclusivamente mediante el uso de uno o varios medio de telecomunicación, como puede ser la venta por correo, internet, teléfono o fax, hasta el momento que se celebra el contrato.

En el caso que un contrato a distancia se celebre por teléfono, el empresario deberá confirma la oferta al consumidor por escrito o, salvo oposición expresa del consumidor y usuario, en cualquier soporte de naturaleza duradera. (Nuevo 98.6 TRLGDCU).

Merece especial atención la redacción dada al artículo 97.1, f, en el que el legislador recoge el contenido mínimo que debe facilitar al consumidor en la información precontractual en el apartado f, indicando el coste de la utilización de la técnica de comunicación a distancia para la celebración del contrato, en caso de que dicho coste se calcule sobre una base diferente de la tarifa básica, pero en ningún momento define o conceptúa la denominación de tarifa básica. 


\section{III.2.4. Derecho de desistimiento}

Las modificaciones introducidas por la presente ley incluyen una mayor precisión en cuanto a la regulación del derecho de desistimiento en los contratos a distancia y los contratos celebrados fuera del establecimiento, regulando un formulario normalizado al respecto que el consumidor podrá utilizar opcionalmente, al tiempo que se amplía el plazo para su ejercicio de 7 días hábiles a 14 días naturales, de conformidad con el Reglamento CEE, Euratom) n. ${ }^{\circ} 1182 / 71$ del Consejo, de 3 de junio de 1971, por el que se determinan las normas aplicables a los plazos, fechas y términos. Además, en caso de que el empresario no facilite al consumidor la información sobre el derecho de desistimiento, se amplía el plazo para desistir del contrato hasta 12 meses después de la fecha de expiración del periodo inicial. La ley regula igualmente las obligaciones que asumen las partes del contrato en caso de desistimiento, así como los efectos del mismo respecto a los contratos complementarios.

Por otra parte, la ley contempla la posibilidad de que el empresario ofrezca al consumidor la opción de cumplimentar un formulario de desistimiento en línea, en cuyo caso deberá proporcionar sin demora indebida un acuse de recibo, por ejemplo, por correo electrónico...»

La carga de la prueba recae sobre el consumidor y por tanto será al que le interese que el medio de prueba haya consistido en un soporte duradero. Si se utiliza la página web del consumidor como instrumento de perfeccionamiento de la relación contractual deberá el empresario proporcionar un documento de desistimiento en línea y un acuse de recibo.

Respecto a los gastos debe el comerciante reembolsar todos los pagos recibidos del consumidor, incluidos los gastos que haya incurrido el comerciante para enviar el producto al consumidor.

Igualmente correrá a cargo del consumidor la depreciación del bien por el uso o consumo. Ahora bien, no queda definido cómo se realiza el cálculo de la depreciación que dependerá del tipo de bien y el uso que realiza el consumidor. Seguramente este aspecto que el legislador ha dejado sin concretar, será una de las causas de controversia entre ambas partes contractuales para poder llevar a efecto el ejercicio del derecho de desistimiento.

El derecho de reembolso comprende todos los gastos incluidos los costes de entrega, salvo que fuera una forma más costosa y elegida 
por el consumidor. La forma de la devolución será el mismo medio de pago siempre que no le suponga gasto adicional.

$\mathrm{Al}$ consumidor le corresponden algunas obligaciones, como devolver el bien antes del transcurso de los 14 días desde que haya comunicado al comerciante su decisión de desistimiento con cargo de los costes directos de la devolución, salvo acuerdo de las partes, y, por supuesto será responsable de la disminución del valor del bien resultante de una manipulación del mismo distinta a la que sea imprescindible para mantener su naturaleza, estado, características.

Por último, destacar que en contratos que vayan unidos a un contrato accesorio de financiación a plazos lógicamente el ejercicio del derecho de desistimiento irá unido a éste, y tendrá como efecto la resolución automática y sin gastos para el consumidor de todo contrato complementario.

\section{CONCLUSIONES}

Como hemos indicado al inicio del trabajo, en el momento de redactarse estas páginas, el proyecto de la nueva Ley General de Defensa de los Consumidores, que se encontraba en fase de debate parlamentario, ha sido aprobado por la Ley 3/2014, de 27 de marzo. Se ha confirmado una aprobación rápida a pesar de las enmiendas planteadas, sustentadas en la extralimitación de las competencias del Estado e invasión de las competencias autonómicas, al igual que se han dejado sin regular aspectos esenciales como la cláusula de permanencia y penalización en caso de baja anticipada, la dudosa aplicabilidad de la exigencia de la firma en los contratos celebrados telefónicamente. Es evidente que supone una mejora en la protección del consumidor al incorporar importantes novedades como que las líneas telefónicas de atención al cliente no pueden suponer un coste superior a la tarifa básica porque el empresario no podrá facturar cargos por el uso de determinados medios de pago que superen el coste al que tiene que hacer frente a ellos por el uso de los mismos, y finalmente que las clausulas abusivas se declararan nulas de pleno derecho y el contrato seguirá vigente con ellas.

Ahora bien, sigue quedando un tanto incompleta la modificación del Texto Refundido ya que debería abarcar a todos los regímenes sectoriales; el legislador europeo podría haber sido más valiente y abarcar en su reforma una regulación mucho más extensa, si bien es cierto que quizá este planteamiento abrirá la discusión doctrinal de 
una armonización plena de la normativa europea y de seguir el modelo de un Código de Consumo.

Con todo ello, podemos indicar que la protección al consumidor se ha consolidado en el marco de las relaciones contractuales, especialmente en los contratos en masa y en las condiciones generales de la contratación, que constituyen una gran parte de las relaciones contractuales que operan en la actualidad en nuestras relaciones domésticas. La protección del consumidor se ha institucionalizado y se ha consolidado como una parte más del propio Derecho. El papel que han desempeñado las Administraciones Públicas y las asociaciones de consumidores en sus primeros momentos ha sido desde luego indispensable y fundamental, así como la mayor participación de las asociaciones empresariales, que lo han entendido como un servicio básico al cliente en sus estrategias comerciales. La protección al consumidor se incrementa cada día a pesar de que existan otras posibles fórmulas que llevarían a una protección todavía más reforzada.

\section{BIBLIOGRAFÍA}

BERCOVITZ RODRÍGUEZ-CANO, A., «Ámbito de aplicación y derechos de los consumidores y usuarios en la Ley General para la Defensa de los Consumidores y Usuarios», Estudios de Consumo, numero 3. 1984.

BERCOVITZ RODRÍGUEZ-CANO, A., Apuntes de derecho mercantil, ed. 14, Editorial Aranzadi, Madrid.

BERMEJO VERA, José, «El derecho a la información de los consumidores», Revista de Estudios de Consumo, 1984, n. ${ }^{\circ} 3$, págs. 86-238.

BERMÚDEZ BALLESTEROS, M. ${ }^{a}$ del Sagrario, «Sanción aplicable al incumplimiento de los deberes de información y documentación sobre el derecho de desistimiento en los contratos celebrados fuera de establecimientos mercantiles: criterios legales y doctrina jurisprudencial». Centro de Estudios de Consumo 2012.

BERMÚDEZ BALLESTEROS, M. ${ }^{a}$ del Sagrario, Revista CESCO de Derecho de Consumo, n. ${ }^{\circ} 1 / 2012$.

BOSCH CAPDEVILLA, Esteve, Nuevas perspectivas del Derecho Contractual, Bosch, 2012. Madrid.

BUSTILLO BOLADO, Roberto O., Convenios y Contratos Administrativos: Transacción, Arbitraje y Terminación Convencional del Procedimiento, Madrid, Aranzadi, 2010. 
CARRASCO BLANCO, Marta, Mediación y consumidores, Ed. Instituto Nacional de Consumo, 2006. Madrid.

DE MARTÍN MUÑOZ, Alberto y HIERRO ANIBARRO, Santiago, Comentarios a la Ley de Arbitraje, Madrid, Marcial Pons, 2006.

DOMINGUEZ PEREZ, Eva, «Recientes planteamientos de tutela del consumidor mediante el ejercicio del derecho de desistimiento» Revista de Derecho de la Unión Europea, n. ${ }^{\circ} 26,1 .^{\circ}$ Semestre 2014 Uned Colex, Madrid.

DIEGUEZ OLIVA, Rocío, «El derecho de desistimiento en el marco común de referencia», In Dret, N. ${ }^{\circ}$ 2/2009.

GARCIA DE ENTERRIA, E., La Constitución como norma jurídica y el Tribunal Constitucional, Civitas Ediciones, S.L., 3. ${ }^{a}$ ed. Madrid. 1988.

GARRIDO FALLA, F., «Introducción general», en El modelo económico de la Constitución, Instituto de Estudios Económicos, 1981.

GARCIA GIL, F. Javier, Suma de la Protección y Defensa de los derechos de los consumidores, DAPP, Publicaciones Jurídicas, 2007.

GUILLEN CARAMES, Javier, El Estatuto Jurídico del Consumidor, Civitas, Madrid, 2002.

LASARTE, Carlos, Contratos, Principios de Derecho Civil III, 13. ${ }^{\circ}$ ed., Marcial Pons, Madrid, 2010.

LINDE PANIAGUA, Enrique, Principios de Derecho de la Unión Europea..$^{\circ}$ ed., Colex Editorial Constitución y Leyes, Madrid, 2012.

- Fundamentos de derecho administrativo: del derecho del poder al derecho de los ciudadanos, Colex Editorial Constitución y Leyes, Madrid 2012.

LINDE PANIAGUA, Enrique y MELLADO PRADO, Pilar, Iniciación al Derecho de la Unión Europea, Colex Editorial Constitución y Leyes, Madrid, 2010.

- Instituciones de derecho comunitario, Colex, 2009

LORCA NAVARRETE, Antonio María, La nueva regulación del arbitraje de consumo, Instituto Vasco de Derecho Procesal, San Sebastián, 2008, pag.43.

ORELLANA CANO, N., "El desistimiento unilateral en los contratos de consumo", en Venta de bienes fuera de establecimiento mercantil, Estudios de Derecho Judicial, n. ${ }^{\circ}$ 3, págs. 1137-3520. 
OROZCO, GUILLERMO y MORENO, MIGUEL ANGEL, «El contrato en el contexto de la unificación del Derecho Privado», Anales del Derecho, número 29, 2011, págs. 115-160.

PANIAGUA ZURERA, Manuel, Movimiento consumerista y movimiento cooperativista, Instituto Nacional de Consumo, 1992.

PASA, Barbara, La forma informativa nel Diritto Contrattuale Europeo verso una nozione procedurale di contrato, Universidad de Torino, Memorie del Dipartimento de Scienze Giuridiche, Jovene EditoreNapoli, 2008.

PATTI, Salvatore, Diritto Privato e Codificazioni Europee, Giuffré Editore-Milano 2004.

POLO Eduardo, La protección del consumidor en el Derecho privado, Editorial Civitas, Madrid 1980 págs. 44 a 85.

REBOLLO PUIG, M., «Derecho administrativo sancionador», Justicia Administrativa. Revista de Derecho Administrativo, núm. 28, 2005.

SAINZ-CANTERO CAPARRÓ M. ${ }^{\mathrm{a}}$ B S, (2008) «El desistimiento ad nutum en los consumidores tras la ley 44/2006 y el Texto Refundido 1/2007 de la Ley General para la Defensa de los Consumidores y Usuarios y otras Leyes complementarias», Actualidad Civil, n. ${ }^{\circ} 9$.

ZIMMERMANN, R., El nuevo Derecho alemán de obligaciones. Un análisis desde la Historia y el Derecho Comparado, Barcelona, págs. 248-254

ZURILLA CARIÑANA, M. ${ }^{\mathrm{a}}$ Ángeles, Alcance y límites de la armonización del derecho de desistimiento en el Texto Refundido de la Ley General para la Defensa de los Consumidores y Usuarios, 2009. 